Article

\title{
Effects of Pulsed Electric Field Treatment on Compression Properties and Solutes Diffusion Behaviors of Jerusalem artichoke
}

\author{
Zhenzhou Zhu ${ }^{1}$, Rui Zhang ${ }^{2, *}$, Nabil Grimi ${ }^{2}$ and Eugene Vorobiev ${ }^{2}$ \\ 1 College of Food Science and Engineering, Wuhan Polytechnic University, Wuhan 430023, China; \\ zhenzhouzhu@126.com \\ 2 Laboratoire Transformations Intégrées de la Matière Renouvelable (UTC/ESCOM, EA 4297 TIMR), \\ Centre de recherche Royallieu, Université de Technologie de Compiègne, CS 60319, \\ 60203 Compiègne Cedex, France; nabil.grimi@utc.fr (N.G.); eugene.vorobiev@utc.fr (E.V.) \\ * Correspondence: rui.zhang@utc.fr; Tel.: +33-344234442; Fax: +33-344231980
}

Academic Editor: Derek J. McPhee

Received: 15 January 2019; Accepted: 31 January 2019; Published: 3 February 2019

\begin{abstract}
Jerusalem artichoke is widely used as raw material for industrial production of inulin. Pressing (compression) and diffusion are two effective technologies for bio-compounds' recovery from plants. In this work, pulsed electric field (PEF) treatment at 400, 600, and $800 \mathrm{~V} / \mathrm{cm}$ during $100 \mathrm{~ms}$ was applied to facilitate juice and solutes recovery from Jerusalem artichoke. The application of PEF led to electroporation of cell membranes and enhanced the tissue compression/juice expression and solutes diffusion. The consolidation coefficient (calculated by application of semi-empirical model) of PEF treated sample at $800 \mathrm{~V} / \mathrm{cm}$ was $6.50 \times 10^{-7} \mathrm{~m}^{2} / \mathrm{s}$, which is significantly higher than that of untreated sample $\left(5.02 \times 10^{-9} \mathrm{~m}^{2} / \mathrm{s}\right)$ and close to that of freeze-thawed sample. Diffusion experiments with PEF treated samples were carried out at 25, 50, and $75^{\circ} \mathrm{C}$. A PEF treatment of Jerusalem artichoke at $800 \mathrm{~V} / \mathrm{cm}$ led to a similar diffusion behavior at $25^{\circ} \mathrm{C}$, compared to diffusion behavior obtained from untreated sample at $75^{\circ} \mathrm{C}$.
\end{abstract}

Keywords: pulsed electric field; compression kinetic; diffusion; Jerusalem artichoke; inulin

\section{Introduction}

Inulin is a kind of fructan, which is widely used in food products for fat replacement and calorie reduction [1]. Although, inulin is presented in various plants, the raw materials for industrial production are chicory root and Jerusalem artichoke [2,3]. Chicory root, which is mainly planted in Europe (especially Belgium), is considered to be the most adapted plant for the industrial production of inulin [4]. Due to climate reasons, Jerusalem artichoke is widely planted in China and is the most important material for inulin production in China [3].

Conventionally, hot water extraction at $70-80^{\circ} \mathrm{C}$ during $1.5-2 \mathrm{~h}$ is applied for inulin extraction $[5,6]$. The high temperature and prolonged duration ensure the extraction yield, however, leads to penetration of impurities (for instance proteins and colorants) into the extract due to the breakage of cellular membranes and cell walls. Consequently, the purification process needs complex steps, such as clarifying, filtration, and decoloration $[7,8]$, implying important waste water emission and high energy consumption.

To search for alternative technologies for inulin extraction with higher purity and less energy consumption, various investigations have been carried out [2,3,9]. The application of pulsed electric fields (PEF) with very short duration (generally from several microseconds to several milliseconds) was effective for compounds' extraction from plants, thanks to the formation of cell membrane pores 
temporarily or permanently [10-15]. For chicory root, PEF pre-treatment $(600 \mathrm{~V} / \mathrm{cm}, 50 \mathrm{~ms})$ gave an inulin extraction yield at $60^{\circ} \mathrm{C}$ that was comparable with that obtained at $80^{\circ} \mathrm{C}$ without PEF treatment, and with an even higher purity [2,13]. However, to our best knowledge, PEF assisted inulin extraction from Jerusalem artichoke was not investigated until now.

Apart from aqueous extraction, pressing is other unit operation to separate liquid containing compounds from the solid-liquid matrix by mechanical compression. The application of PEF to assist the compression process has also been carried out. Mhemdi et al. [16] investigated combined pressing-diffusion technology for sugar beets pretreated by PEF. The results indicated that with PEF assisted pressing, sugar beet slices were better exhausted, permitting a reduction of the sucrose loss in pulp from $1.2 \%$ to $0.8 \%$, and extracted more concentrated sucrose that was less colored and purer than that conventionally extracted by diffusion. A detailed investigation about the effect of PEF treatment on the pressing behavior of sugar beet tissue was also reported [17]. The calculated consolidation coefficient (filtration diffusivity) revealed that a PEF treatment of $600 \mathrm{~V} / \mathrm{cm}$ during $10 \mathrm{~ms}$ induced better compression than that without PEF treatment. Grimi et al. [18] explained that the PEF treatment led to the removal of the entrapped air by the liquid released from the electroporated cells, thus modifying the compressibility of the tissue. Until now, the PEF assisted pressing of Jerusalem artichoke was not investigated.

The aim of this work is to study the effect of PEF treatment (with differing intensity) on the compression kinetics and filtration diffusivity of the Jerusalem artichoke (Figure 1), and to evaluate its influence on inulin extraction. For this purpose, PEF treatments at 400, 600, and $800 \mathrm{~V} / \mathrm{cm}$ were applied to assist the compression and diffusion process. Consolidation coefficients characterizing the filtration diffusivity and diffusion behavior are investigated.

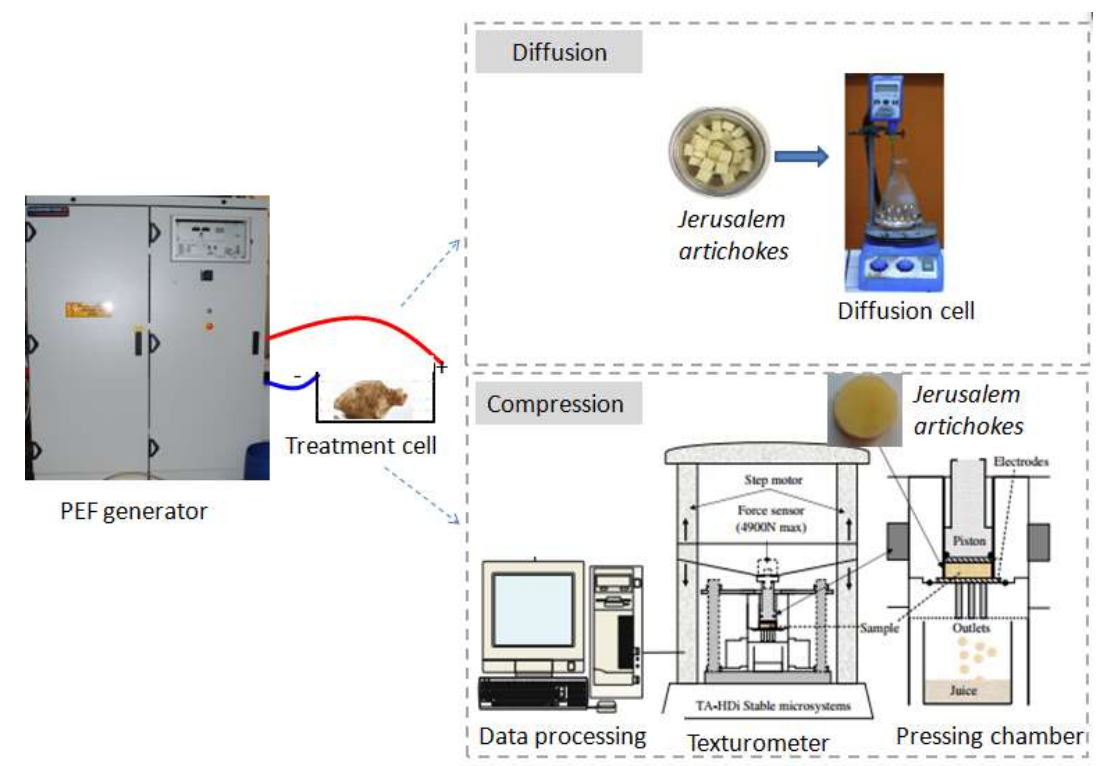

Figure 1. Set-up used for pulsed electric fields (PEF) treatment, texture analysis, and diffusion.

\section{Results and Discussion}

\subsection{Deformation Curves and Data Computing}

Figure 2 represents the relative deformation, $\epsilon$ vs. $t^{1 / 2}$, for untreated, PEF treated, and freeze-thawed Jerusalem artichokes samples. Since the loading time required for attaining the fixed constant-pressure (4 bar) was very short, the loading of samples is assumed to be quasi-instantaneous. For untreated samples, a quasi-immediate elastic deformation was obtained in almost $5 \mathrm{~s}$. The relative deformation reached 0.22 in $5 \mathrm{~s}$. It should also be noted that the deformation curve presents two obvious steps: almost linear at the beginning of the compression (first step), and a slow deformation until the end of 
the compression (second step). Comparatively, PEF treatment and freeze-thawed treatment led to more important deformation of samples. For example, the final relative deformation reached $0.44,0.78$, and 0.88 for PEF treated samples under 400,600, and $800 \mathrm{~V} / \mathrm{cm}$, respectively. In fact, previous studies have shown that PEF treatment at 400,600, and $800 \mathrm{~V} / \mathrm{cm}$ could lead to different degrees of tissue electroporation, thus resulting in differing compression behavior [19]. The freeze-thawed treatment resulted in the highest final relative deformation.

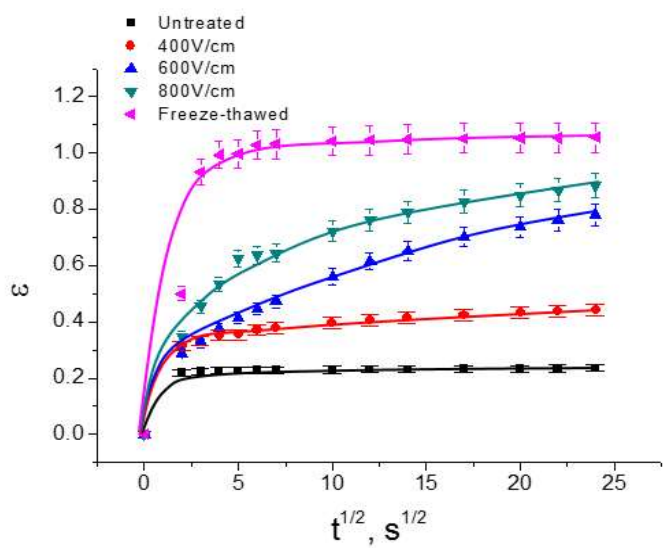

Figure 2. Deformation, $\varepsilon$, vs. $t^{1 / 2}$ for untreated, PEF treated, and freeze-thawed samples.

Figure 3 represents the deformation curve in coordinates $\frac{t}{\varepsilon^{2}}$ vs. $t$ according to Equation (4). This good linear correlation between $\frac{t}{\varepsilon^{2}}$ and $t$ validate the applicability of the above equations for compression tests with Jerusalem artichoke tissue, and was used to find the slope $c$, and to calculate the value of $\varepsilon_{\infty}$. The values of $\varepsilon_{\infty}$ obtained from Figure 3 for different treatments are presented in Figure 4 . The maximal relative deformation varied according to the treatments. PEF treatment significantly increased the maximal relative deformation of samples due to the better electroporation of tissue. At the highest values of PEF intensity, the increase of $\varepsilon_{\infty}$ became less pronounced. For example, the value of $\varepsilon_{\infty}$ increased from 0.44 to 0.82 when the electric field strength increased from $E=400$ to $E=600 \mathrm{~V} / \mathrm{cm}$, while $\varepsilon_{\infty}$ reached 0.90 at $E=800 \mathrm{~V} / \mathrm{cm}$. At this value of $E, \varepsilon_{\infty}$ was close to that obtained for freeze-thawed sample. However, it should be noted that the $\varepsilon_{\infty}$ value also depends on the applied pressure [20].

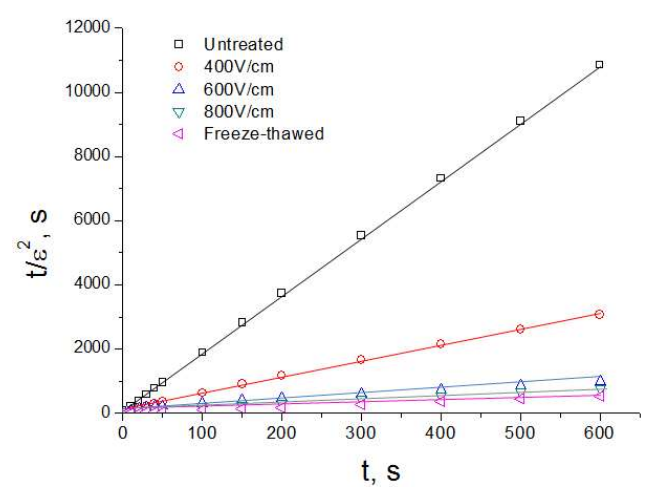

Figure 3. $\frac{t}{\varepsilon^{2}}$ vs. $t$ for the untreated, PEF treated, and freeze-thawed samples. 


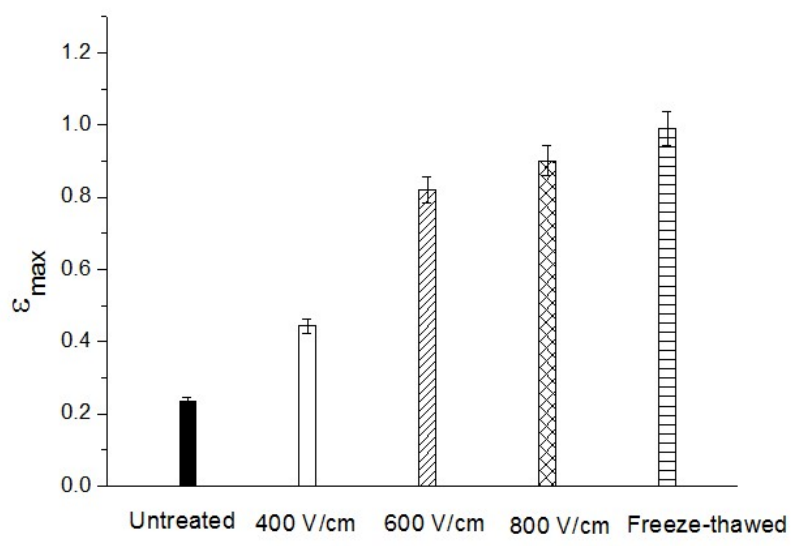

Figure 4. $\varepsilon_{\infty}$ for the untreated, PEF treated, and freeze-thawed samples.

Curves of $U$ vs. $t^{1 / 2}$ allow the calculation of the consolidation coefficient, $b$. One example of this is presented in Figure 5. The slope of the initial part of the $U$ vs. $t^{1 / 2}$ relationship corresponds to Equation (3), from which the value of $b$ can be determined. Figure 6 shows the values of the consolidation coefficient, $b$, for the untreated and PEF treated samples. More intensive PEF treatment led to the higher values of $b$. Closed values of $b$ for the sample treated by PEF at $E=800 \mathrm{~V} / \mathrm{cm}$ and for the freeze-thawed sample indicate the efficiency of PEF for Jerusalem artichoke tissue. The value of the maximal consolidation coefficient of Jerusalem artichoke tissue seems comparable with that of sugar beet, which was reported previously $[17,18]\left(4 \times 10^{-7} \mathrm{~m}^{2} / \mathrm{s}\right)$, implying the similar compressibility of these two plant materials.

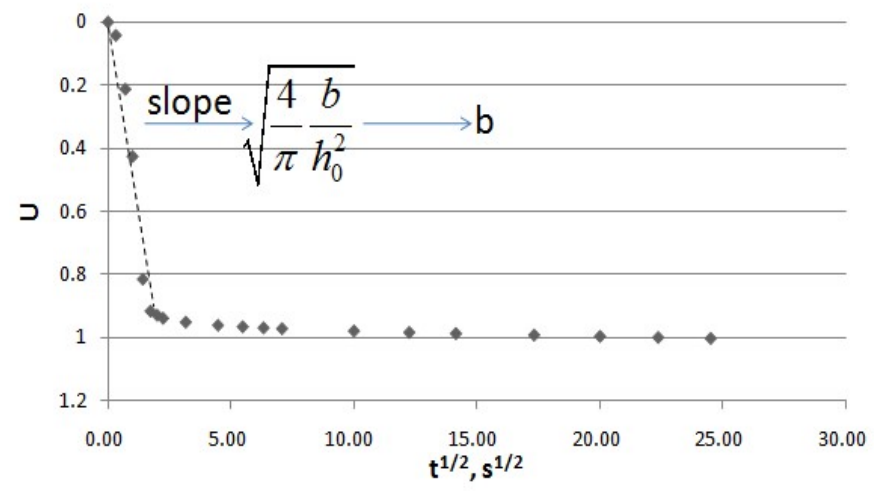

Figure 5. $U$ vs. $t^{1 / 2}$ for the determination of $b$.

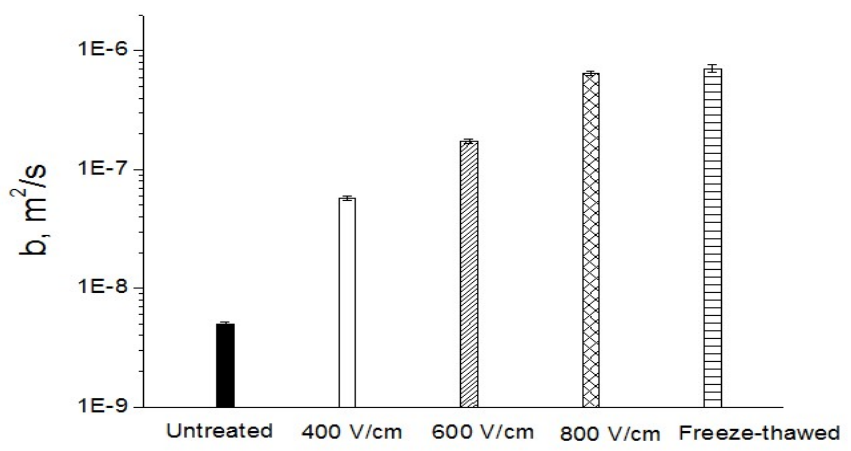

Figure 6. Coefficient for the untreated, PEF treated, and freeze-thawed samples.

\subsection{Diffusion}

Diffusion experiments at 25,50 , and $75{ }^{\circ} \mathrm{C}$ were carried out to evaluate the effect of the pre-treatment and diffusion temperature on soluble matter extraction. Figure 7 shows the 
solute extraction kinetics from Jerusalem artichokes untreated, PEF treated $(E=400-1000 \mathrm{~V} / \mathrm{cm})$, and freeze-thawed. The results are presented in the form:

$$
B=\frac{{ }^{0} \text { Brix }^{0}-{ }^{0} \text { Brix }_{i}}{{ }^{0} \text { Brix }_{f}-{ }^{0} \text { Brix }_{i}}
$$

where ${ }^{0} \mathrm{Brix}_{i}$ and ${ }^{0} \mathrm{Brix}_{f}$ are the initial and final soluble matter contents, respectively, and $B$ is the normalized function of ${ }^{0}$ Brix. The value of ${ }^{0} \mathrm{Brix}_{i}$ was determined immediately after placing Jerusalem artichokes into the diffusion cell, and ${ }^{0} \mathrm{Brix}_{f}=4.0 \pm 0.2$ was determined after $2 \mathrm{~h}$ of extraction at $80^{\circ} \mathrm{C}$.

A previous study [2] showed a good linear correlation $\left(R^{2}=0.97\right)$ between the inulin (measured by HPLC) and the soluble matter content $\left({ }^{\circ}\right.$ Brix) in the extracted juice from chicory roots. Here, we suppose that the total solutes' extraction kinetics from Jerusalem artichokes corresponds roughly to the variation of the inulin content during the extraction experiment. The data presented in Figure 7 show that more rapid diffusion kinetics can be achieved at higher diffusion temperatures. The maximal value of $B$ for the untreated sample was 0.78 , corresponding to the diffusion temperature of $75^{\circ} \mathrm{C}$. However, the same value of $B$ was achieved by freeze-thawing at $25^{\circ} \mathrm{C}$, indicating that the diffusion temperature might be reduced after pretreatments. Figure $7 \mathrm{~b}-\mathrm{d}$ revealed that PEF treatment accelerated the solute diffusion, especially at low diffusion temperatures $\left(25^{\circ} \mathrm{C}\right)$. However, for the diffusion at $75^{\circ} \mathrm{C}$, the positive influence of PEF treatment was lower. These results revealed that the denaturation of plant tissue can be caused by both thermal and electrical treatment. To reach a satisfactory solute diffusion, an effective PEF pre-treatment can lead to less thermal treatment requirements, therefore, reducing the diffusion temperature.
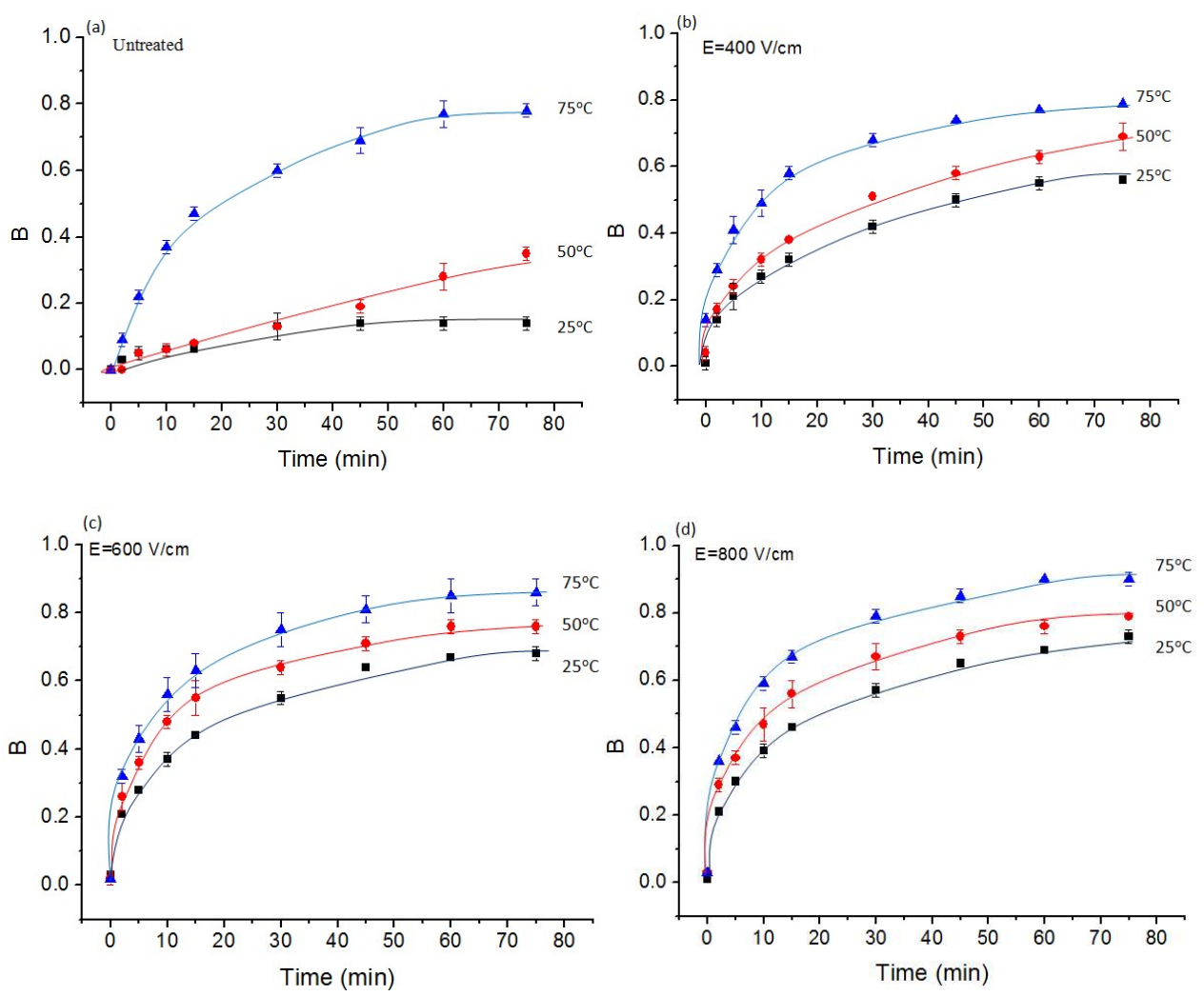

Figure 7. Cont. 


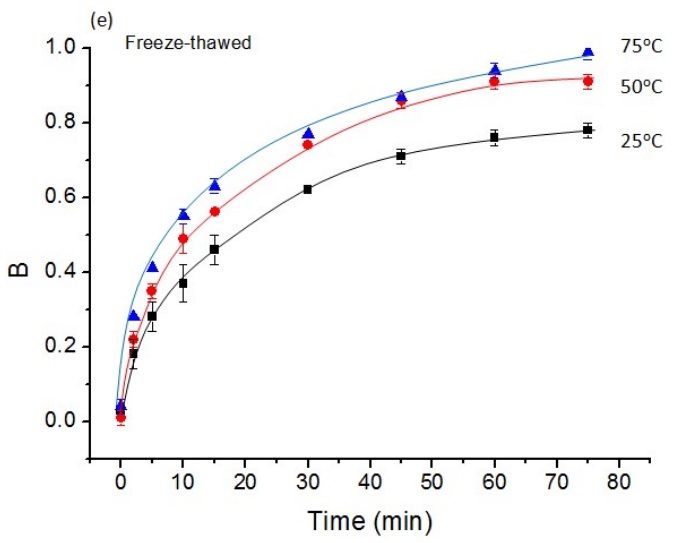

Figure 7. Normalized Brix function, $B$, during aqueous extraction from untreated (a), PEF treated at $400 \mathrm{~V} / \mathrm{cm}(\mathbf{b}), 600 \mathrm{~V} / \mathrm{cm}(\mathbf{c}), 800 \mathrm{~V} / \mathrm{cm}(\mathbf{d})$, and freeze-thawed (e) Jerusalem artichokes.

\section{Materials and Methods}

\subsection{Materials}

Commercial Jerusalem artichokes were selected as the raw material for investigation. Samples of good and uniform quality were purchased from the supermarket (Compiegne, France). The samples were stored at $4{ }^{\circ} \mathrm{C}$ until required. The moisture content of Jerusalem artichokes was within $75 \%-80 \%$. Freeze-thawed sample was prepared at $-18^{\circ} \mathrm{C}$ for $24 \mathrm{~h}$, followed by thawing of the sample at ambient temperature. The rectangle-shaped samples, which were $5 \mathrm{~mm}$ high, $10 \mathrm{~mm}$ long, and $10 \mathrm{~mm}$ wide, were prepared for diffusion experiments. Cylinder-shaped samples (diameter $d=25 \mathrm{~mm}$ and height $h=10 \mathrm{~mm}$ ) were prepared for compression experiments using a texture analyzer (model TA-XT Plus, Stable Microsystems, Surrey, England).

\subsection{PEF Treatment}

PEF treatment was carried out using a PEF generator, 5 kV-1 kA (Hazemeyer, Saint-Quentin, France) (Figure 1). The whole sample of Jerusalem artichokes was used in the PEF treatment process. The samples were placed in the PEF treatment cell. The PEF treatment cell was composed of two plane electrodes $(120 \mathrm{~mm} \times 205 \mathrm{~mm})$ and filled with distilled water media to obtain a good contact. The distance between the two electrodes was fixed at $6 \mathrm{~cm}$, which corresponded to a treatment volume of $1.48 \times 10^{-3} \mathrm{~m}^{3}$. The value of the electric field strength, $E$, was evaluated as $E=U / d(\mathrm{~V} / \mathrm{cm})$, where $U$ $(\mathrm{V})$ was the applied voltage and $d(\mathrm{~cm})$ was the distance between the two electrodes. The PEF generator provided pulses of a near-rectangular shape. In the present study, 10 trains, where 100 pulses with a duration of $t_{i}=100 \mu \mathrm{s}$ in each, was applied. The pause between individual trains was $\Delta t=10 \mathrm{~s}$. The total time of the PEF treatment was $100 \mathrm{~ms}$. The choice of PEF treatment time was based on a previous study of PEF assisted solute extraction from chicory roots [21]. The electrical field strength was varied from $400-800 \mathrm{~V} / \mathrm{cm}$.

\subsection{Diffusion Experiments}

The instrument for the extraction of soluble matter from Jerusalem artichokes was a Fisher Scientific laboratory apparatus(San Jose, CA, USA) equipped with a magnetic stirrer (-Thermo Fisher, San Jose, CA, USA) and digital thermo regulator (10-1300 $\mathrm{min}^{-1}$, Thermal Fisher, San Jose, CA, USA) (Figure 1). The extraction experiments were conducted in a glass round-bottomed flask with rectangle-shaped samples $(80 \mathrm{~g})$ and distilled water. The distilled water was preheated at the desired temperature $\left(25^{\circ} \mathrm{C}\right.$, $50^{\circ} \mathrm{C}$, and $75^{\circ} \mathrm{C}$, respectively), then rectangle-shaped samples were placed into the extraction cell. In every extraction test, the liquid to solid radio was fixed at $4(w / w)$. The speed of agitation was fixed at $150 \mathrm{rpm}$. 
To measure the soluble matter content $\left({ }^{\circ}\right.$ Brix, $\left.\%\right), 1 \mathrm{~mL}$ of the solution was taken at $0,2,5,10,15$, $30,45,60$, and $75 \mathrm{~min}$. The round-bottomed flask was covered by aluminum foil during experiments to avoid any evaporation. The soluble matter content $\left({ }^{\circ}\right.$ Brix, \%) was measured by a digital Atago refractometer (PR-101, Atago, 50 Tokyo, Japan).

\subsection{Compression Test}

The compression test was carried out with a texture analyzer (model TA-XT Plus, Stable Microsystems, Surrey, England) equipped with a $4905 \mathrm{~N}$ load cell (Figure 1). It consists of a pressing piston and a cylinder-shaped force senor (diameter of $25 \mathrm{~mm}$ ), both made of stainless steel. The cylinder-shaped samples (diameter of $25 \mathrm{~mm}$ and height of $10 \mathrm{~mm}$ ) were placed over the cylinder-shaped force senor. A stainless-steel pressing piston with a force of $200 \mathrm{~N}$ (which is the maximum force offered by the applied equipment, and the pressure corresponds to 4 bar), moving at a speed of $1 \mathrm{~mm} / \mathrm{s}$, was used to evaluate the deformation of the sample. The thickness $(h)$ of the sample during compression was recorded by the equipped computational software (Texture Expert Exceed). The deformation was defined as $\varepsilon=1-h_{t} / h_{0}$, where $h_{t}$ and $h_{0}$ are the current and initial thickness of the specimen, respectively. Then, the displacement-time curve was analyzed. For good experimental practice, all tests were run on the same day the samples were processed.

\subsection{Statistic Analysis}

All the tests were repeated at least three times. Data were expressed as the mean \pm standard deviation (SD).

\subsection{Solid-Liquid Expression Model}

Although the mechanism of solid-liquid expression from plant materials is still under investigation, the filtration-consolidation theory is currently widely adopted for simulation of the mechanical expression of cellular materials [17,22-24]. According to this theory, with the assumptions that the plant tissue is composed of compressible porous materials and an average filtration diffusivity exists during the consolidation process, the following equation was developed, presenting the relationship between consolidation ratio $(U)$ and expression time $(t, s)[18,25,26]$ :

$$
U=\frac{\Delta h}{\Delta h_{\infty}}=\frac{\varepsilon}{\varepsilon_{\infty}}=\frac{\left[\frac{4}{\pi} \frac{b}{h_{0}^{2}} t\right]^{0.5}}{\left[1+\left(\frac{4}{\pi} \frac{b}{h_{0}^{2}} t\right)^{v}\right]^{0.5 / v}}
$$

where $\Delta h=h_{0}-h, \Delta h_{\infty}=h_{0}-h_{\infty}, h_{0}(\mathrm{~m})$ and $h(\mathrm{~m})$ are the initial and actual sample thickness, $\varepsilon=\frac{\Delta h}{\Delta h_{0}}$ and $\varepsilon_{\infty}=\frac{\Delta h_{\infty}}{\Delta h_{0}}$ are the actual and infinite relative deformation, respectively, $b\left(\mathrm{~m}^{2} / \mathrm{s}\right)$ is the consolidation coefficient characterizing filtration diffusivity, and $v$ is the consolidation behavior index.

From Equation (2), the following relation is proposed [25] for the small values of $t$ :

$$
U=\left[\frac{4}{\pi} \frac{b}{h_{0}^{2}} t\right]^{0.5}
$$

Then, the value of $b$ could be obtained from the slope of the plot, $U$ vs. $t^{1 / 2}$.

The infinitive relative deformation, $\varepsilon$, can be obtained from the relation $[27,28]$ :

$$
\frac{t}{\varepsilon^{2}}=a+c t
$$

where $a$ and $c$ are constants. According to Equation (4), the value of $c$ can be found from the slope of the plot, $\frac{t}{\varepsilon^{2}}$ vs. $t$. From Equation4, at infinite time, $c t \gg a$, thus $\varepsilon_{\infty}=1 / \sqrt{c}$. After obtaining the value of 
$\varepsilon_{\infty}$, the value of $U$ can be found, then the consolidation coefficient, $b$, can be determined from the slope of the curve, $U$ vs. $t^{1 / 2}$ (Equation (3)).

\section{Conclusions}

PEF pre-treatment at 400,600, and $800 \mathrm{~V} / \mathrm{cm}$ was applied to enhance the tissue compression and solutes' extraction from Jerusalem artichokes. The relative deformation was approximately 0.9 after $800 \mathrm{~V} / \mathrm{cm}$ PEF treatment during $100 \mathrm{~ms}$, close to that obtained by freeze-thawing. Consolidation coefficients of untreated, PEF treated, and freeze-thawed samples were determined by application of the semi-empirical model. The consolidation coefficient of the PEF treated sample at $800 \mathrm{~V} / \mathrm{cm}$ was $6.50 \times 10^{-7} \mathrm{~m}^{2} / \mathrm{s}$, significantly higher than that of the untreated sample $\left(5.02 \times 10^{-9} \mathrm{~m}^{2} / \mathrm{s}\right)$, and close to that of the freeze-thawed sample. Diffusion experiments led to the determination of solute diffusivity from the untreated and PEF treated tissue. The electric field intensity $(E)$ showed great influence on the diffusion behavior. Both the compression and diffusion tests evidenced that a PEF treatment of $800 \mathrm{~V} / \mathrm{cm}$ was sufficient for electroporation of Jerusalem artichokes. Nearly the same diffusion behavior was attained for the untreated sample at $75^{\circ} \mathrm{C}$ and the PEF treated $(800 \mathrm{~V} / \mathrm{cm})$ sample at $25^{\circ} \mathrm{C}$. This gives an interesting perspective for the new technologies of "cold" extraction from Jerusalem artichokes.

Author Contributions: Z.Z., R.Z., N.G. and E.V. conceived, designed and carried out the experiments. R.Z. and Z.Z. analyzed the data and wrote the paper. N.G. and E.V. wrote and reviewed the paper before submitting.

Funding: This research was funded by National Natural Science Foundation of China, grant number 21506166.

Conflicts of Interest: The authors declare no conflicts of interest.

\section{References}

1. Villegas, B.; Costell, E. Flow behavior of inulin-milk beverages. Influence of inulin average chain length and of milk fat content. Int. Dairy J. 2007, 17, 776-781. [CrossRef]

2. Zhu, Z.; Bals, O.; Grimi, N.; Vorobiev, E. Pilot scale inulin extraction from chicory roots assisted by pulsed electric fields. Int. J. Food Sci. Tech. 2012, 47, 1361-1368. [CrossRef]

3. Wei, L.Y.; Wang, J.H.; Zheng, X.D.; Teng, D.; Yang, Y.L.; Cai, C.G.; Feng, T.H.; Zhang, F. Studies on the extracting technical conditions of inulin from Jerusalem artichoke tubers. J. Food Eng. 2007, 79, 1087-1093.

4. Apolinário, A.C.; de Lima Damasceno, B.P.G.; de Macêdo Beltrão, N.E.; Pessoa, A.; Converti, A.; da Silva, J.A. Inulin-type fructans: A review on different aspects of biochemical and pharmaceutical technology. Carbohydr. Polym. 2014, 101, 368-378. [CrossRef] [PubMed]

5. Franck, A.; De Leenheer, L. Inulin. In Biopolymers Online; Wiley-VCHVerlagGmbH\&Co.KGaA: Berlin, Germany, 2005.

6. Zhu, Z.; He, J.; Liu, G.; Barba, F.J.; Koubaa, M.; Ding, L.; Bals, O.; Grimi, N.; Vorobiev, E. Recentin sights for the green recovery of inulin from plant food materials using non-conventional extraction technologies: Areview. Innov. Food Sci. Emerg. 2016, 33, 1-9. [CrossRef]

7. Arsem, W.C. Extraction and Purification of Inulin. U.S. Patent 1,616,167, 1 February 1927.

8. Zhu, Z.; Li, S.; He, J.; Thirumdas, R.; Montesano, D.; Barba, F.J. Enzyme-assisted extraction of polyphenol from edible lotus (Nelumbo nucifera) rhizomek not: Ultra-filtration performance and HPLC-MS ${ }^{2}$ profile. Food Res. Int. 2018, 111, 291-298. [CrossRef] [PubMed]

9. Li, W.; Zhang, J.; Yu, C.; Li, Q.; Dong, F.; Wang, G.; Gu, G.; Guo, Z. Extraction, degree of polymerization determination and prebiotic effect evaluation of inulin from Jerusalem artichoke. Carbohydr. Polym. 2015, 121, 315-319. [CrossRef]

10. Weaver, J.C.; Chizmadzhev, Y.A. Theory of electroporation: A review. Bioelectrochem. Bioenerg. 1996, 41, 135-160. [CrossRef]

11. Loginov, M.; Loginova, K.; Lebovka, N.; Vorobiev, E. Comparison of dead-end ultrafiltration behavior and filtrate quality of sugar beet juices obtained by conventional and "cold" PEF-assisted diffusion. J. Membr. Sci. 2011, 377, 273-283. [CrossRef] 
12. Moubarik, A.; El-Belghiti, K.; Vorobiev, E. Kinetic model of solute aqueous extraction from Fennel (Foeniculum vulgare) treated by pulsed electric field, electrical discharges and ultrasonic irradiations. Food Bioprod. Process. 2011, 89, 356-361. [CrossRef]

13. Zhu, Z.; Bals, O.; Grimi, N.; Ding, L.; Vorobiev, E. Qualitative characteristics and dead-end ultrafiltration of chicory juice obtained from pulsed electric field treated chicories. Ind. Crop. Prod. 2013, 46, 8-14. [CrossRef]

14. Almohammed, F.; Mhemdi, H.; Vorobiev, E. Purification of juices obtained with innovative pulsed electric field and alkaline pressing of sugar beet tissue. Sep. Purif. Technol. 2017, 173, 156-164. [CrossRef]

15. Pelletier, S.; Serre, É.; Mikhaylin, S.; Bazinet, L. Optimization of cranberry juice deacidification by electro dialysis with bipolarmembrane: Impact of pulsed electric field conditions. Sep. Purif. Technol. 2017, 186, 106-116. [CrossRef]

16. Mhemdi, H.; Bals, O.; Vorobiev, E. Combined pressing-diffusion technology for sugar beets pretreated by pulsed electric field. J. Food Eng. 2016, 168, 166-172. [CrossRef]

17. Mhemdi, H.; Bals, O.; Grimi, N.; Vorobiev, E. Filtration diffusivity and expression behavior of thermally and electrically pretreated sugar beet tissue and press-cake. Sep. Purif. Technol. 2012, 95, 118-125. [CrossRef]

18. Grimi, N.; Vorobiev, E.; Lebovka, N.; Vaxelaire, J. Solid-liquid expression from denaturated plant tissue: Filtration-consolidation behaviour. J. Food Eng. 2010, 96, 29-36. [CrossRef]

19. Zhu, Z.; Bals, O.; Grimi, N.; Ding, L.; Vorobiev, E. Better damage of chicory tissue by combined electroporation and ohmic heating for solute extraction. Food Bioprod. Process. 2015, 94, 248-254. [CrossRef]

20. Grimi, N.; Lebovka, N.; Vorobiev, E.; Vaxelaire, J. Compressing behavior and texture evaluation for potatoes pretreated by pulsed electric field. J. Texture Stud. 2009, 40, 208-224. [CrossRef]

21. Loginova, K.V.; Shynkaryk, M.V.; Lebovka, N.I.; Vorobiev, E. Acceleration of soluble matter extraction from chicory with pulsed electric fields. J. Food Eng. 2010, 96, 374-379. [CrossRef]

22. Buttersack, C. Two-zone model for solid-liquid separation by filtration and expression. Chem. Eng. Sci. 1994, 49, 1145-1160. [CrossRef]

23. Lanoisellé, J.L.; Vorobyov, E.I.; Bouvier, J.M.; Pair, G. Modeling of solid/liquid expression for cellular materials. Alche J. 1996, 42, 2057-2068. [CrossRef]

24. Wongkittipong, R.; Prat, L.; Damronglerd, S.; Gourdon, C. Solid-liquid extraction of andrographolide from plants-experimental study, kinetic reaction and model. Sep. Purif. Technol. 2004, 40, 147-154. [CrossRef]

25. Shirato, M.; Murase, T.; Atsumi, K. Simplified computational method for constant pressure expression of filter cakes. J. Chem. Eng. Jpn. 1980, 13, 397-401. [CrossRef]

26. Andersen, N.P.R.; Christensen, M.L.; Keiding, K. New approach to determining consolidation coefficients using cake-filtration experiments. Powder Technol. 2004, 142, 98-102. [CrossRef]

27. Bouzrara, H.; Vorobiev, E. Solid-liquid expression of cellular materials enhanced by pulsed electric field. Chem. Eng. Process. Process Intensif. 2003, 42, 249-257. [CrossRef]

28. Peleg, M. Characterization of the stress relaxation curves of solid foods. J. Food Sci. 1979, 44, $277-281$. [CrossRef]

Sample Availability: Samples of the compounds are not available from the authors.

(C) 2019 by the authors. Licensee MDPI, Basel, Switzerland. This article is an open access article distributed under the terms and conditions of the Creative Commons Attribution (CC BY) license (http:/ / creativecommons.org/licenses/by/4.0/). 